\title{
Research on the Scope Definition of Contractor's
}

\author{
Reasonable Proposals \\ Zhang $\mathrm{Xi}^{1}$ and Ke Hong ${ }^{2}$ \\ ${ }^{1,2}$ School of Management, Tianjin University of Technology, Tianjin, China \\ ${ }^{1} 1098534430 @ q q . c o m$
}

Keywords: Reasonable proposals; Value engineering; Scope definition

\begin{abstract}
As to the phenomenon of variation order sum accounting for construction settlement more and more,this paper put forward the effective way of the contractor proposing reasonable proposals in which the construction cost can be reduced and the project value can be improved.Define the scope of contractor's reasonable proposals is the critical problem.Therefore,this paper defines the concept and contents of the contractor's reasonable proposals by means of literature research and case analysis, which make the scope of contractor's reasonable proposals be clear.
\end{abstract}

\section{Introduction}

Variation order probability contractor putting forward is lower than that of employer. Code bills quantities and valuation for construction works(GB 50500-2013) has viewed variation as an significant research direction and defined variation as three main forms--bill of quantities gaps, project characteristics inconsistent, quantity deviation, so that variation control will be more sophisticated. Thus, The right of variation on the one side of employer is imparted by literatures and engineering contract specifications. That is to say, employer can ask contractor to execute variation on his own, not needing the consent of contractor. And unless contractor cannot implement this variation, otherwise, the instructions of employer's variation shall not be refused. In addition, 10.2term "Right of variation" explicitly pointed out that both employer and supervisor can put forward variation, but constructor can not make any variation for any part of the project on his own. From the relationship of right, we draw the conclusion that the employer takes the initiative, while the contractor stands by the side. In the construction practice, the employer is regarded as the main control to variation, while the contractor is limited to suggest variation. Therefore, an important research direction-managing and controlling employer's variation arises.

Greatly adjustment of the price caused by the employer's variation. The uncertainty of the construction project leads to the variation which influences the construction cost directly, outstandingly and realistically. In turn, Variation produces the uncertainty of the construction project and the increase of construction's risk repeatedly, therefore, the increased cost has become a "bottomless pit".

Practical engineering cases proved that the amount employer's variation brings generally accounts for more than 3\% of the settlement price of the project, more than $20 \%$ to $30 \%$, even more. That design variation and other reasons can cause about 6\% 20\% engineering price changes, which 
accounted for a greater proportion in the construction projects, mostly over $20 \%$, sometimes even reaching the $40 \%$ or so ${ }^{[1]}$. For instance, the road from the Buddha to Foshan Kaiping City, until the end of June 1996, the variation employer proposed due to various reasons has been measured and paid to 7934.1 million yuan which accounts for $30.7 \%$ of completed construction cost, 25873.5 million yuan in the same period ${ }^{[2]}$.

Above all, the contractor's reasonable proposals is an another important way to controlling engineering investment. And defining the scope of contractor's reasonable proposals is the key to realizing the effective control of engineering investment. Thus, this paper adopts the method of literature research and case analysis to research it.

\section{Concept definition of contractor's reasonable proposals}

Concept definition of contractor's reasonable proposals in the laws and regulations. Reasonable proposals concept was originally proposed by the object of enterprise, which are mostly applied to the enterprise management to improve the current enterprise operation , management system and the quality of the products; simplify the process, save materials and working time; improve production safety, protect environment and labor.

Reasonable proposals refers that the contractor proposes to the employer(supervisor), involving the design drawings, construction scheme, the variation of construction organization design and placing new materials and equipment, aiming at optimizing technical and economic indicators of the construction and (or) operation period so that reaching the effect of reducing the engineering investment. The contractor's proposal should not only point out the existing problems and shortcomings, but also put forward the corresponding solutions and suggestions. After the proposals by the employer through the audit, the contractor establishes the corresponding construction schemes and implement. This term first appeared in the 99 edition of "construction contract model text", but there was no detailed specification for it. After that, Although there is no reasonable proposals of wording in Construction conditions of contract (99 edition), but the "written proposal" in "' terms and " reasonable proposals" is interlinked in essence. Subsequently, The 07 edition of

the standard construction tender documents make classification for reasonable proposals. The detailed provisions of the reasonable proposals in contract texts are shown in Table 1.1. 
Table 1.1 Contractor's reasonable proposals under the different contracts

\begin{tabular}{|c|c|c|c|}
\hline Name & $\begin{array}{c}\text { Construction project } \\
\text { demonstration text of } \\
\text { construction contract } \\
\text { (2013 edition) } \\
\end{array}$ & $\begin{array}{l}\text { construction conditions } \\
\text { of contract( } 99 \text { edition) }\end{array}$ & $\begin{array}{l}\text { Standard construction } \\
\text { tender documents(2007 } \\
\text { version) }\end{array}$ \\
\hline $\begin{array}{l}\text { Provision } \\
\text { name }\end{array}$ & $\begin{array}{l}\text { Reasonable proposals of } \\
\text { contractor }\end{array}$ & Value engineering & $\begin{array}{l}\text { Reasonable proposals } \\
\text { of contractor }\end{array}$ \\
\hline $\begin{array}{l}\text { Contents } \\
\text { of } \\
\text { reasonable } \\
\text { proposals }\end{array}$ & $\begin{array}{l}\text { The contractor who put } \\
\text { forward reasonable proposal } \\
\text { shall submit the instruction to } \\
\text { the supervisor, which includes } \\
\text { the content and reason of } \\
\text { suggestion and the impact on } \\
\text { the price and the duration of } \\
\text { the contract after } \\
\text { implementing the proposals }\end{array}$ & $\begin{array}{l}\text { Including all contents of } \\
\text { construction project }\end{array}$ & $\begin{array}{l}\text { The contractor shall } \\
\text { submit to the supervisor } \\
\text { in written form for the } \\
\text { reasonable suggestions } \\
\text { provided by the } \\
\text { contractor for the } \\
\text { drawings, technical } \\
\text { requirements and other } \\
\text { aspects of the contract. } \\
\text { documents. }\end{array}$ \\
\hline $\begin{array}{l}\text { Effect of } \\
\text { reasonable } \\
\text { proposals }\end{array}$ & $\begin{array}{l}\text { Reduce the contract price or } \\
\text { improve the economic benefits } \\
\text { of the project }\end{array}$ & $\begin{array}{l}\text { Shorten the duration, } \\
\text { Lower the cost of life } \\
\text { cycle ,Improve the } \\
\text { efficiency or value after } \\
\text { the completion of the } \\
\text { project }\end{array}$ & $\begin{array}{l}\text { Reduce the contract } \\
\text { price, shorten the } \\
\text { construction duration、 } \\
\text { improve the economic } \\
\text { benefits of the project }\end{array}$ \\
\hline
\end{tabular}

Obviously, the full specification of reasonable proposals is out of the 07 version of the "standard construction tender documents". Thus, according to it, we can analysis and draw the conclusion that define the concept " reasonable proposals "as these proposals put in the construction stage, mainly relating to the variation of the design drawings, construction conditions, construction organization design, materials, equipment which based on reducing the construction price, shorten the construction duration, increasing the economic benefits of the project or bringing other benefits.

Concept definition of contractor's reasonable proposals under the theory of value engineering. (1)Theory of value engineering. Value Engineering (VE) is also called Value Analysis(VA). The theory of value engineering aims at making the object equip with necessary function in the lowest cost, which is combined with the technical and economic to make the improved function and reduced cost unify in the optimal scheme. The definition can be illustrated by the following formula.

Value $=$ Function/Cost

Formula (2-1)

(2)Avenue to improving value

According to the definition of value engineering formula, we can deduce from the following five ways to improve the value of the project:

(1) Function unchanged, Cost increased;

(2) Cost unchanged, improved Function;

(3) Function improved, Cost lowed (This is the focus on the research direction of value engineering);

(4) Cost increased slightly, Function improved largely;

(5) Function lowed slightly, Cost lowed largely.

(3)Application of contractor's reasonable proposals under the theory of value engineering 
According to the theory of value engineering analysis, combined with the practical engineering case about contractor's reasonable proposals, we can draw a conclusion that the essence of achieving reasonable proposals is the application to Value Engineering. The whole value of the project's improvement is the premise of the employer's approval of reasonable proposals. During the process of construction, Reasonable proposals put by the contractor based on the theory of value engineering. The employer seeks to improve the value of the project, and at the same time the employer has the right to approve the proposal, therefore, the basic feature of the $\mathrm{r}$ contractor's reasonable proposals is to improving the value of the project. According to the five avenues to improving value engineering, combined with the contractor's reasonable proposals' main forms, the basic path to achieving contractor's reasonable proposals, as shown in figure 1.1 .

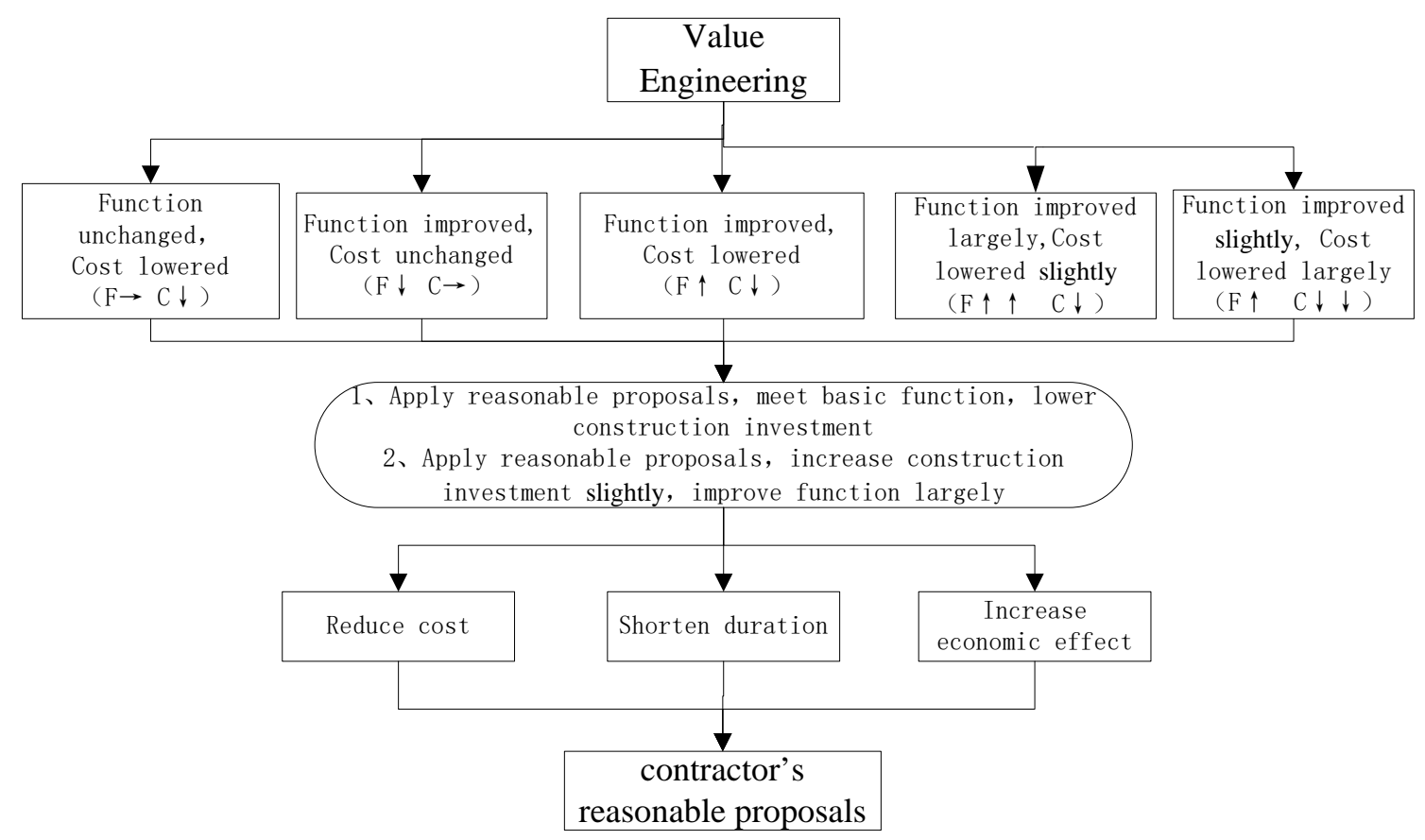

Fig 1.1 Contractor shall implement the basic route of reasonable proposals

From figure 1.1, we conclude that under the theory of value engineering, contractor's reasonable proposals can be defined as" From the interests of both sides, the contractor put the suggestions which can improve the function value of the building, lower the employer's construction investment and shorten the duration .And enhance the practical value of the products is for the purpose."

\section{Content Definition of the contractor's reasonable proposals}

Main circumstances of the contractor's reasonable proposals. According to the analysis and induction of the literature, the classification for the situation of the contractor's reasonable proposals is less. Gao Haichao ${ }^{[4]}$ analysis combining with case ,thinking circumstances of the contractor's reasonable proposals are focused on the following aspects: (1) Other available materials or equipments exist in the construction;(2)An improved design scheme exists in the construction;(3)An improved construction scheme exists in the construction; (4) An improved construction 
technology exists in the construction;(5)Unnecessary projects to be cut exists in the construction;(6)An unnecessary amount of work to be cut exists in the construction. In each case, there are various specific circumstances due to the differences of construction conditions, construction site conditions and the design program. Based on the analysis of literature, combining with the forms and characteristics of variation order, through summing up the practical experience of some workers, form the case summary table 2.1 of contractor's reasonable proposals.

Table 2.1 Cases on contractor rationalization proposal

\begin{tabular}{|c|c|c|c|}
\hline $\begin{array}{l}\text { Cases on contractor's } \\
\text { reasonable proposal }\end{array}$ & Form of proposing & $\begin{array}{l}\text { Classification of } \\
\text { circumstance }\end{array}$ & $\begin{array}{l}\text { Evaluation and } \\
\text { analysis by VE }\end{array}$ \\
\hline $\begin{array}{l}\text { Qingdao Architectural } \\
\text { Engineering College } \\
\text { Huang Dao campus’s } \\
\text { new stadium project }{ }^{[4]}\end{array}$ & $\begin{array}{l}\text { The cost of the } \\
\text { original design } \\
\text { scheme is high and the } \\
\text { duration is long. And } \\
\text { there exists an } \\
\text { improvement. }\end{array}$ & $\begin{array}{c}\text { Improve the } \\
\text { original Design } \\
\text { Scheme }\end{array}$ & $(\mathrm{F} \rightarrow \mathrm{C} \downarrow)$ \\
\hline $\begin{array}{l}\text { School administration } \\
\text { office building's } \\
\text { renovation project }^{[5]}\end{array}$ & $\begin{array}{c}\text { There can be a } \\
\text { substitute for new } \\
\text { materials, and can } \\
\text { save cost. }\end{array}$ & Use other materials & $(\mathrm{F} \rightarrow \mathrm{C} \downarrow)$ \\
\hline $\begin{array}{c}\text { Shanghai Maritime } \\
\text { University’s } \\
\text { Graphic }^{[6]}\end{array}$ & $\begin{array}{l}\text { The cost of the } \\
\text { original design } \\
\text { scheme is high and the } \\
\text { duration is long. And } \\
\text { there exists an } \\
\text { improvement. }\end{array}$ & $\begin{array}{c}\text { Improve the } \\
\text { original Design } \\
\text { Scheme }\end{array}$ & $(\mathrm{F} \rightarrow \mathrm{C} \downarrow)$ \\
\hline $\begin{array}{l}\text { A certain highway } \\
\text { project }^{[7]}\end{array}$ & $\begin{array}{l}\text { In the case of meeting } \\
\text { the design } \\
\text { requirements, there is } \\
\text { a new procurement } \\
\text { plan to reduce the } \\
\text { actual situation of the } \\
\text { construction. }\end{array}$ & Use other materials & $(\mathrm{F} \uparrow \uparrow \mathrm{C} \downarrow)$ \\
\hline
\end{tabular}

Through the above literature and case analysis summary, we can see that the contractor puts forward reasonable proposals from three aspects--materials or equipment, design and cost. And according to different construction conditions, construction site situations and original design scheme, proposing various of suggestion situations.

Specific content of the main circumstances of the contractor's reasonable proposals. (1)Improve Design Scheme. With the construction of the project, whether design scheme is optimized, conforming to the construction site conditions and construction conditions or not is prerequisite for ensuring construction project cost and construction engineering products to be more reasonable and economic. The 
contractor put forward reasonable proposals to improve the design, mainly from the following two aspects considered:

1)Improve the original Design Scheme

In the design stage of construction, due to the objective and subjective factors, the design scheme may exists certain defects. During the process of construction implement, If the item with construction difficulty or conducive to the construction conditions exists in the design scheme, After analysising specific advantages and disadvantages of construction condition, the contractor can adopt other design scheme which can not only improve the beauty of building, applicability and function of housing, but also reduce the cost. Improving design scheme is a selective variation. Generally speaking, during the construction process, as to the design scheme, the contractor puts forward reasonable proposals of improvement due to the following main factors:

(1)Changes of the construction conditions

In the process of construction, due to the early geological prospecting phase is not exhaustive, if the contractor found design does not match with the actual situation, he can put forward reasonable proposals of improvement in order to guarantee the reasonable planning of construction project, proper design of buildings, smooth construction and normal utility and reduce the damage to the employer.

\section{(2)Errors or omissions of design}

In the design stage, errors or omissions exists in the design scheme due to the following factors: Designers doesn't have a deep understand for the site, resulting in the design is not just right; Design does not pay attention to the application of value engineering or comparison and selection of schemes, resulting in engineering technology and engineering economy unhooking seriously; Design unit is only responsible for the technology and is not clear to the economic responsibility, resulting in errors or omissions existing in the design scheme. Thus, the contractor can propose reasonable proposals for the improvement of the design scheme. If the contractor finds the above situations during the process of construction, he can propose reasonable proposals based on the following reasons:

--Improving the original design scheme to shorten the duration

-- Improving the original design scheme to shorten the duration greatly, but the investment of the project increasing slightly

-- Improving the original design scheme to shorten the duration, decreasing the investment of the project

The above three forms achieve the final effect of enhancing the value of the project by shortening the investment or a small increase in investment projects based on a substantial increase engineering function under the premise of the whole function value.

2)Delete redundant projects in the original design scheme

During the process of construction, the contractor proposes reasonable proposals of deleting unnecessary items owing to the over-conservative original design and favorable construction conditions. Under normal circumstances, the contractor 
proposes reasonable proposals under the ground of shortening duration and decreasing investment.

(2)Use other materials

Construction which account for $50 \% \sim 70 \%$ of the total cost of construction project material is the material foundation of construction. In addition, It's quality directly affects the quality of the project. Choosing building materials correctly not only ensures the quality of the project, but also is an important avenue to reducing the construction cost. Therefore, optimizing the building materials further in the construction stage is of necessary. The materials that can meet the requirements of construction are not unique, there are many alternative. Thus, when the contractor proposes reasonable proposals of using other materials, he can consider from the following two aspects:

1)Use alternative materials

In the course of the project implementation, the construction materials or equipment with difficulty to be acquired can be replaced by other materials or equipment. Under normal circumstances, the reason why the contractor proposes reasonable proposals to employer is that purchasing materials is of difficulty as well as shortening the duration. The shortened duration of the project will lead to a reduction in the overall project cost, with the overall investment reduced, but the overall function of the project unchanged, improving the value of the project.

2)Use new materials

The contractor proposes to use new materials on the ground of the improvement and upgrade of the efficiency and quality level of construction. Specifically speaking, the beauty degree of building's appearance can be upgraded greatly by new materials to meet the increasing aesthetic needs of the people. If the cost of using new materials or equipment is higher than that of the original material or equipment, the contractor can propose reasonable proposals for increasing investment slightly, with improving the overall function value largely, resulting in enhancing the value.

If the contractor finds the above circumstances during the process of construction, he can propose reasonable proposals under the following two reasons:

(1) Use other materials can shorten the duration;

(2)Use other materials can shorten the duration largely, but increase investment slightly.

\section{Conclusion}

The contractor, direct producer of construction, can put forward effective and economical reasonable proposals by right of rich work experience, which creates good prerequisite for the smooth implementation of the project and lowers the risk in the construction process. By analysising the literature, combined with the practical engineering case, with using value engineering theory, define the scope of reasonable proposals as: the variation proposals are put forward in the phrase of construction, mainly including design drawings, construction conditions, construction organization design, materials and equipment. They start from a point of reducing the cost of the 
project investment, shortening the duration of the project, and improving the value of the project. And summarizes the main situations in which the contractor puts forward reasonable proposals: improving design scheme and using other materials. Hope the above conclusions are of great benefit to construction practice.

\section{References}

[1]Huo Xinxi. Design variation and construction instruction management[J]. Architecture of Shanxi, 2007(17):265-266.

[2]Chen Ning, Yang Zanfeng. Impact of variation project on project investment[J]. Journal of Wuhan communication science and Technology University,1998,22(2):166-168.

[3]Gao Haichao. Research on the contractor's revenue management under the condition of variation order[D].Tian Jin: Tianjin University of Technology,2011.

[4]Lu Peimeng, Hong Wenxia. Focus on reasonable proposals to reduce cost[J]. Economist,2004(3),17.

[5]He Debin. Application of value engineering in cost control of construction project implementation stage[J]. Architecture of Cichuan, 2010(4):250-251.

[6]Yang Qunrong. Research on the economic benefit of the optimization of the construction process of large scale comprehensive engineering and the adoption of reasonable proposals[J]. Building construction,2011(10):941-943.

[7]Zhang Longping. Variation order and claim tactics in highway construction project[J].Highways and cars,2007(2):124-126. 